\title{
Microdeposits of amyloid in sclerocalcific heart valves: a histochemical and immunofluorescence study
}

\author{
YA GOFFIN, ${ }^{*}$ W MURDOCH, $\dagger$ GG CORNWELL III, $\uparrow$ GD SORENSON $\dagger$
}

From the *Department of Pathology, Hospital Universitaire Brugmann, Université Libre de Bruxelles, Belgium and the †Departments of Medicine and Pathology, Dartmouth Medical School, Hanover, New Hampshire, USA

SUMMARY Amyloid associated with seven sclerotic and two normal aortic and mitral valves was studied. The sclerotic valve amyloid contained microfibrils with typical random orientation and a fibril width of $9.5-12.5 \mathrm{~nm}$. The amyloid deposits demonstrated permanganate-resistant Congophilia and contained the amino acid tryptophan. Immunofluorescence studies showed P-component in amyloid deposits of 6 of 7 valves, but none of the sclerotic valves contained amyloid fibril proteins of the $\mathrm{AL}$ (primary), $\mathrm{AA}$ (secondary), $\mathrm{AE}_{\mathrm{t}}$ (medullary thyroid carcinoma) or $\mathrm{ASc}_{1}$ (senile cardiac) types. Two non-sclerotic valves, removed from a patient with systemic amyloidosis, showed permanganate-sensitive Congophilic amyloid deposits which contained amyloid fibril protein AA.

The deposition of amyloid fibrils in the heart valves is a well known occurrence in the primary (AL), myeloma-associated $(\mathrm{AL})$ and senile $\left(\mathrm{ASc}_{1}\right)$ forms of systemic amyloidosis.' Recently, a fourth type of valvular amyloidosis has been reported independently from four laboratories: ${ }^{2-5}$ a localised form of amyloid deposition appearing exclusively and with high incidence in sclerotic and particularly in sclerocalcific valves. The deposits are small and restricted to the areas of scarring and calcification, and their incidence does not correlate with the age of the patients. This form of amyloid is apparently of dystrophic type, but a biochemical marker of the amyloid fibrils has not yet been found. The purpose of this study was to characterise the morphological and chemical nature of dystrophic valvular amyloid.

\section{Accepted for publication 28 June 1983}

Abbreviations used in this paper are in part derived from guidelines adopted at the Third Symposium on Amyloidosis held in Povoa de Varzim, Portugal in September 1979: ASC $=$ amyloid fibril protein from senile cardiac amyloid; ASoA = senile aortic amyloid; IAA = isolated atrial amyloid; HPA = human prealbumin; $\mathbf{A A}=$ amyloid fibril protein $A ; A \lambda I, A \lambda I V, A \lambda V I$ immunoglobin light chain amyloid fibril proteins of the $\lambda I, \lambda I V$ and $\lambda V I$ subgroups; $A_{t}=$ amyloid fibril protein from medullary carcinoma of the thyroid; AP $=$ amyloid P-component.

\section{Material and methods}

\section{TISSUES}

Heart valves containing amyloid were selected by the macroscopic iodine test. One sample of each positive and negative valve was fixed in $10 \%$ formalin and embedded in paraffin. Six $\mu \mathrm{m}$ sections were then stained with alkaline Congo red, and amyloid was defined by its selective apple green birefringence in polarised light.

Eight mitral and four aortic valves with the following characteristics were studied: seven sclerocalcific amyloid-laden valves; one sclerocalcific mitral valve without amyloid; one mitral and one aortic valve of normal structure, containing small deposits of amyloid from a patient with systemic reactive (secondary) amyloidosis; one completely normal mitral valve; and one completely normal aortic valve. Details of the tissues are provided in Table 1.

An additional specimen of each valve was snap frozen directly, kept at $-20^{\circ} \mathrm{C}$, washed in cold $0.15 \mathrm{M}$ phosphate-buffered saline (PBS) at $\mathrm{pH} \mathrm{7.2,}$ fixed in ethanol and embedded in paraffin. ${ }^{6}$ Six $\mu \mathrm{m}$ sections were deparaffinised ${ }^{6}$ just prior to conducting histochemical or immunofluorescence studies. Initially, sections made from both frozen and paraffin blocks were studied, but since no differences were observed with the two procedures, all 
Table 1 Histological findings of heart valves

\begin{tabular}{|c|c|c|c|c|}
\hline $\begin{array}{l}\text { Tissue } \\
\text { no }\end{array}$ & $\begin{array}{l}\text { Sex } \\
\text { age }(y r)\end{array}$ & Valve & Histology & Amyloid* \\
\hline $\begin{array}{l}1 \\
2+ \\
3 \\
4\end{array}$ & $\begin{array}{l}\text { F } 22 \\
\text { M } 55 \\
\text { F } 28 \\
\text { F } 51\end{array}$ & $\begin{array}{l}\text { Mitral } \\
\text { Mitral } \\
\text { Mitral } \\
\text { Mitral }\end{array}$ & $\begin{array}{l}\text { Non-sclerotic } \\
\text { Non-sclerotic } \\
\text { Chronic rheumatic disease } \\
\text { Sclerosis and fused } \\
\text { commissure, aetiology } \\
\text { unknown }\end{array}$ & $\overline{+}(\mathbf{A A})$ \\
\hline $\begin{array}{l}5 \\
6 \\
7\end{array}$ & $\begin{array}{l}\text { M } 49 \\
\text { F } 57 \\
\text { F } 52\end{array}$ & $\begin{array}{l}\text { Mitral } \\
\text { Mitral } \\
\text { Mitral }\end{array}$ & $\begin{array}{l}\text { Chronic rheumatic disease } \\
\text { Chronic rheumatic disease } \\
\text { Sclerosis and calcification, } \\
\text { aetiology unknown }\end{array}$ & $\begin{array}{l}+ \\
+ \\
+\ddagger\end{array}$ \\
\hline 8 & F 56 & Mitral & $\begin{array}{l}\text { Sclerosis, aetiology } \\
\text { unknown }\end{array}$ & \\
\hline $\begin{array}{l}9 \\
10+ \\
11 \\
12\end{array}$ & $\begin{array}{l}\text { M } 46 \\
\text { M } 55 \\
\text { F } 51 \\
\text { M } 65\end{array}$ & $\begin{array}{l}\text { Aortic } \\
\text { Aortic } \\
\text { Aortic } \\
\text { Aortic }\end{array}$ & $\begin{array}{l}\text { Non-sclerotic } \\
\text { Non-sclerotic } \\
\text { Chronic rheumatic disease } \\
\text { Calcified bicuspid valve. }\end{array}$ & $\begin{array}{l}- \\
+(\mathbf{A A}) \\
+\ddagger \\
+\end{array}$ \\
\hline
\end{tabular}

*Amyloid determined by alkaline Congo red method.

†Tissues no 2 and no 10 were derived from the same patient. ¥Amyloid fibrils detected by electron microscopy.

subsequent studies were carried out with paraffin sections only.

\section{ELECTRON MICROSCOPY}

Two sclerotic mitral valves and two sclerotic aortic valves, all containing amyloid deposits, were fixed in $1 \%$ buffered osmium tetroxide, stained with uranyl acetate and embedded in Epon. Thin sections were stained with lead acetate, then examined and photographed on a Philips 201 electron microscope.

\section{HISTOCHEMISTRY}

Potassium permanganate treatment of sections prior to alkaline Congo red staining was performed by the method of Wright et al. ${ }^{7}$ Tryptophan was detected by the desoxymethylaminobenzene (DMAB) method. ${ }^{8}$ Fluorescence Congo red was performed as described below.

\section{ANTISERA}

Antisera to various amyloid fibril proteins were raised in rabbits and absorbed to specificity as previously described..$^{910}$ Non-immune rabbit serum was used as a control. Rabbit antihuman prealbumin (HPA) and goat anti-P component (AP) were purchased from Calbiochem-Behring and Atlantic Antibodies Inc, respectively.

\section{IMMUNOFLUORESCENCE}

Frozen and paraffin sections were studied by indirect immunofluorescence. ${ }^{9}$ Since sclerotic tissue displayed strong autofluorescence, tissue sections were stained with Congo red prior to incubation with antisera, in order to suppress the background fluorescence. This procedure was carried out by immersing sections in $0.05 \%$ Congo red (in $50 \%$ ethanol) for $3 \mathrm{~s}$ followed by washing in distilled water. Potassium hydroxide destaining was not used. Slides were then immersed at room temperature in PBS for $15 \mathrm{~min}$, counterstained with 5-10 $\mu \mathrm{l}$ of appropriate antiserum dilution (generally $1 / 16$ or $1 / 32$ ), washed and stained with fluorescein isothiocyanate (FITC)-conjugated goat anti-rabbit or rabbit antigoat IgG. This fluorescence Congo red method allowed the initial identification of amyloid by its green birefringence in polarised light and by its bright red fluorescence through a green absorption filter (Zeiss No 487715) in UV light. Amyloid identified in this way could then be examined for specific green immunofluorescence by switching directly to an FITC filter (Zeiss No 487711) using a twin-lamp Zeiss photomicroscope III.

\section{Results}

\section{ELECTRON MICROSCOPY}

Fibrils with characteristic ultrastructure of amyloid were found in the sclerotic areas of two valves of the four studied. One mitral (no 7) (Fig. 1) and one aortic (no 11) valve contained abundant microfibrils (9.5-12.5 $\mathrm{nm}$ width) with typical random orientation. Some fine granular material blending with the fibrils and a few collagen fibres were observed in the same areas. One sclerotic mitral valve (no 8) contained very few small fibrils and one sclerotic aortic valve (no 12) did not show any fibrils in the sections studied.

HISTOCHEMISTRY AND IMMUNOFLUORESCENCE The results of the histochemical and immunofluorescence studies are presented in Table 2. All amyloid deposits tested contained tryptophan. Congo red staining of amyloid associated with sclerotic valves was resistant to permanganate treatment but, as expected, amyloid of the AA type was permanganate-sensitive.

Anti-AP antiserum did not react with normal valves or the sclerotic mitral valve without amyloid. All amyloid-containing valves studied with anti-AP gave a positive reaction, except for one mitral valve (no 6). The reaction of amyloid with anti-AP was strong at the periphery of the amyloid deposits and showed a linear pattern within the deposits (Fig. 2). Vessel walls were strongly positive, whereas some collagen fibres reacted weakly.

Anti-SAA, an antiserum previously shown to react specifically with amyloid of the AA type, reacted strongly with amyloid of tissues no 2 (Fig. $3 a, 3 b, 3 c, 3 d)$ and no 10 , but failed to react with other heart valves. Antisera specific for amyloid 


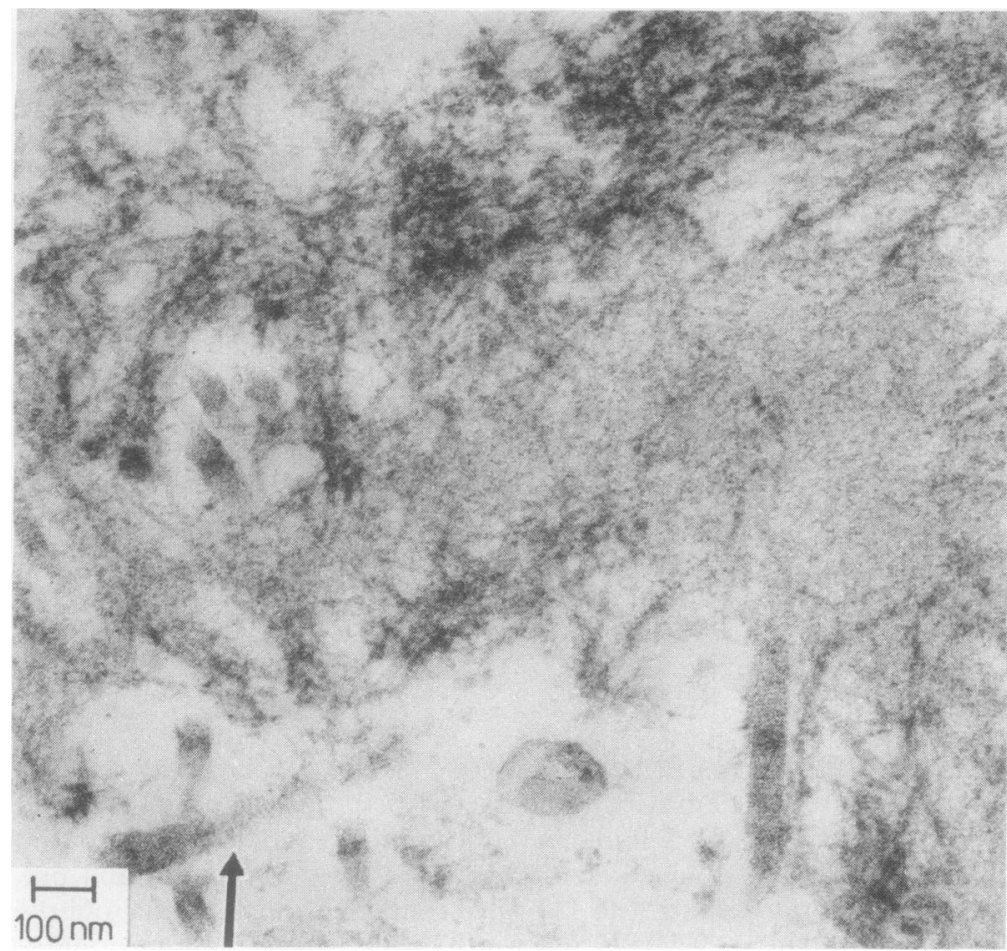

Fig. 1 Electron micrograph of amylo렬 fibre (arrow) $\times 60000$.

Table 2 Histochemical and immunoftuorescence reactions of heart valves

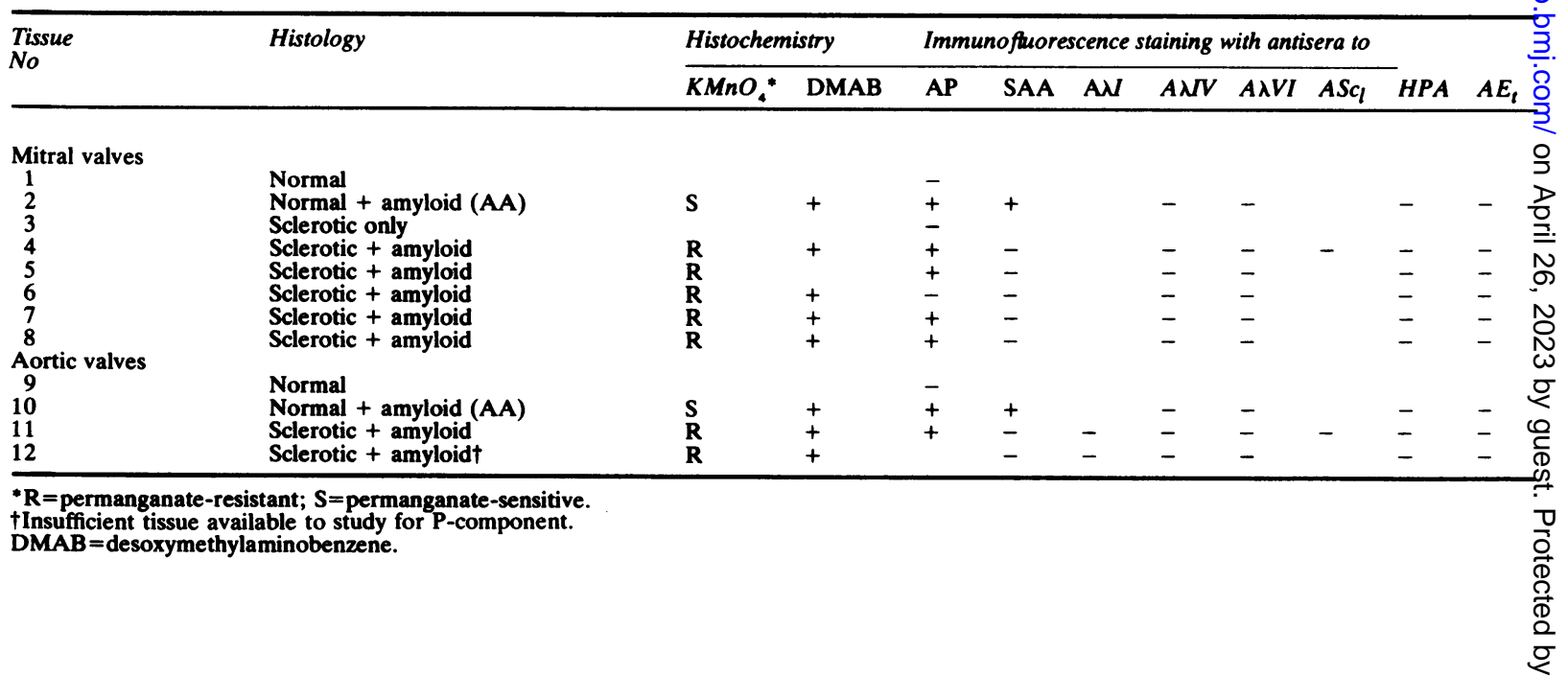




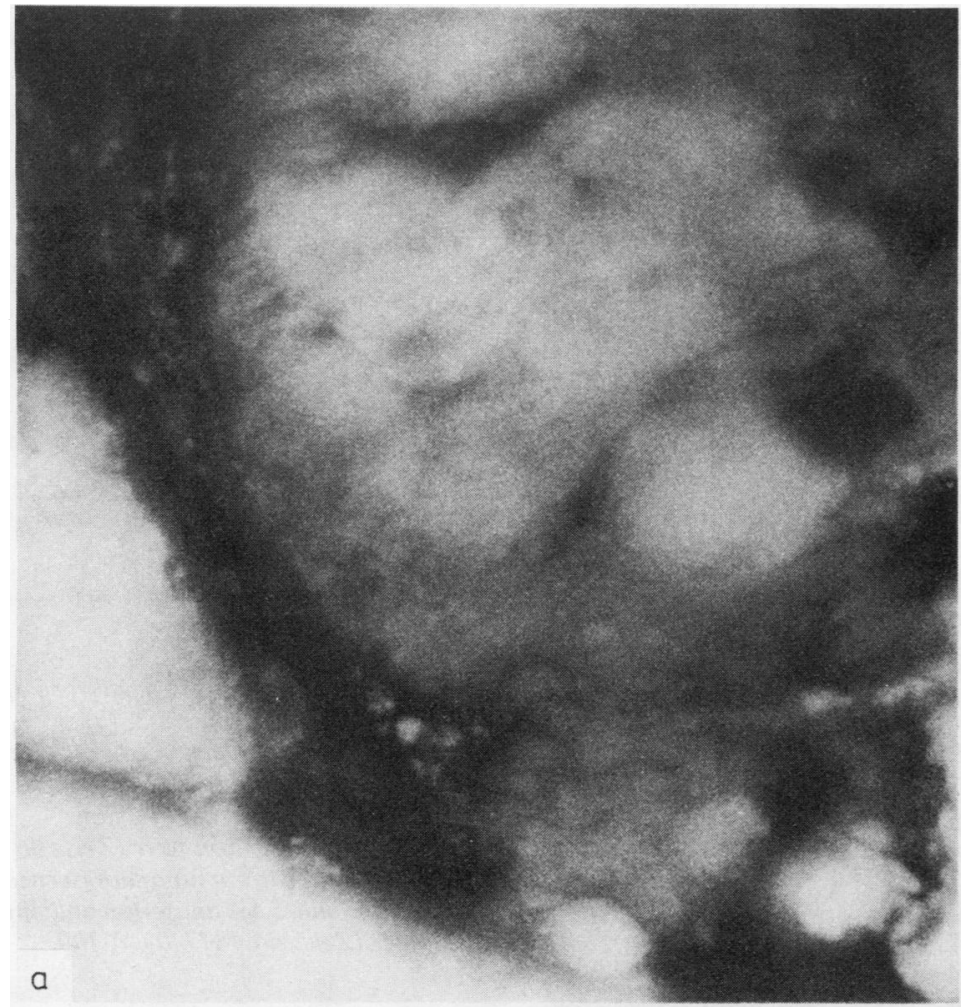

Fig. 2 Amyloid deposits in sclerotic mitral valve no 8. (a) Congo red fuorescence reaction. Original magnification $\times 250$.

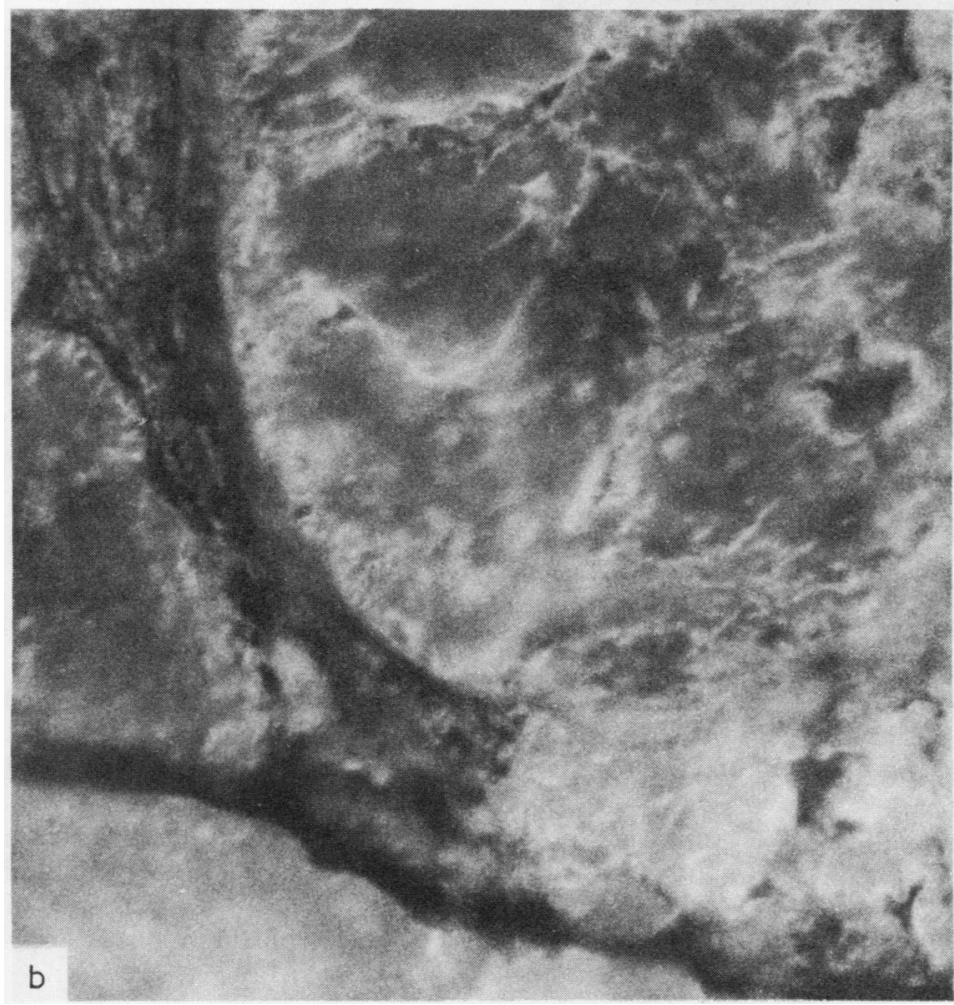
(b) Immunofuorescence reaction with anti-AP antiserum. Original magnification $\times 250$. 

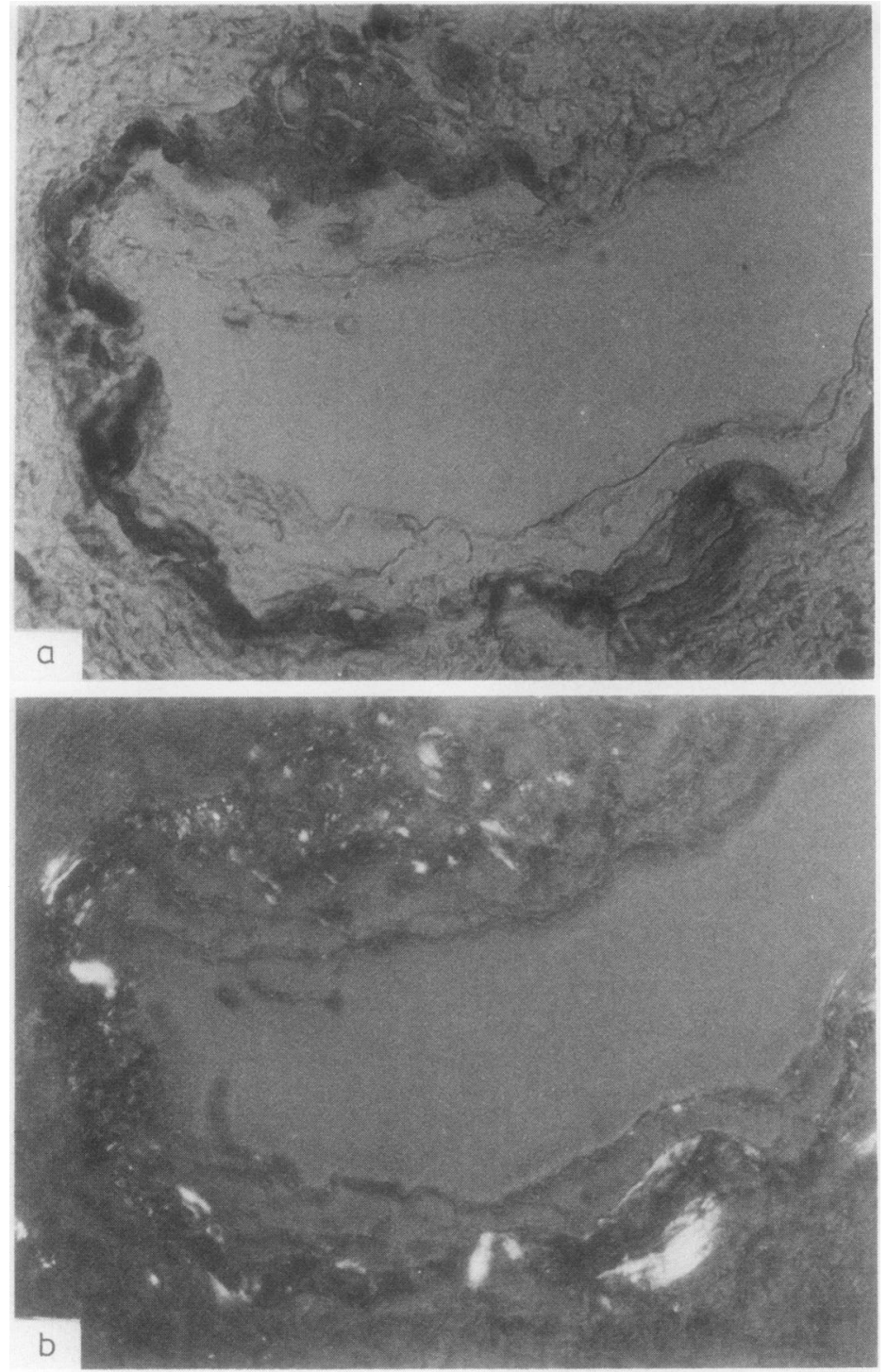

Fig. 3 Amyloid deposits in the fibrosa of $\frac{\mathrm{N}}{\mathrm{N}}$ non-sclerotic mitral valve no 2. (a) alcoholic Congo red reaction in ordinary light $\times 250$. (b) in polarised light $\times 250$. (c) Congo red fuorescence reaction utilizing green absorption filter (Zeiss no 487715) $\times 300$. (d) immunofuorescence reaction with anti-SAA antiserum utilizing FITC filter (Zeiss no 487711) $\times 300$. fibril proteins $A \lambda I, A \lambda I V, A \lambda V I, A S q$ and $A_{t}$ were non-reactive with all amyloid deposits tested. Anti-HPA was similarly free of reactivity.

\section{Discussion}

The localised amyloid deposits associated with sclerotic heart valves have several characteristics which are common to most forms of amyloid studied N thus far. The deposits demonstrated typical $\underset{\mathrm{C}}{\mathrm{N}}$ permanganate-resistant birefringence in polarised $O$ light when stained with Congo red. To date, per- 0 manganate sensitivity has been observed only in $\overparen{D}$ amyloid of the AA type ${ }^{7}$ and in amyloid associated $\stackrel{\mathscr{C}}{+}$ with seminal vesicles. ${ }^{11}$ The ultrastructure of $\square$ amyloid microfibrils showed typical random orienta- 


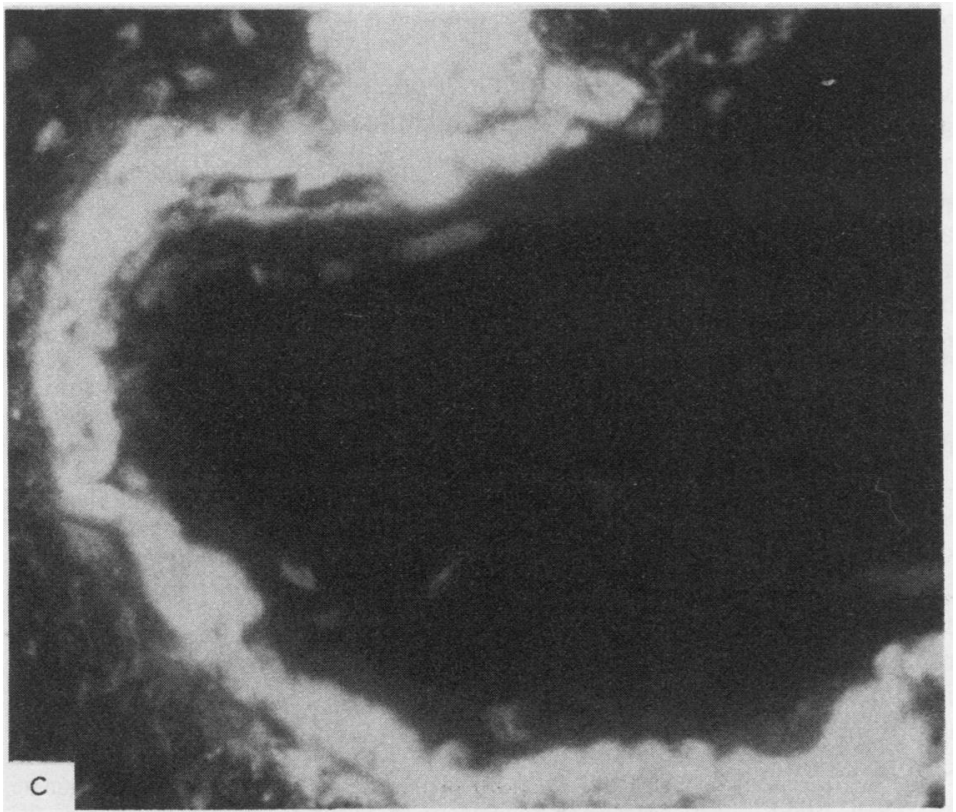

tion with a fibril width of 9.5 to $12.0 \mathrm{~nm}$. These fibrils are somewhat larger than those reported in other forms of amyloid, but are similar in size to those recorded recently in other studies of sclerotic heart valves ${ }^{24}$ and in senile plaques associated with Alzheimer's disease. ${ }^{12}$

This type of amyloid contained tryptophan, an amino acid which has thus far been found in all types of amyloid except those associated with insulinoma, pancreatic islets, ${ }^{11}$ medullary carcinoma of the thyroid, ${ }^{13}$ senile cardiac amyloid of the isolated atrial type, ${ }^{14}$ seminal vesicles ${ }^{11}$ and some forms of cerebral amyloid. ${ }^{15}$ In addition, dystrophic amyloid contained P-component (AP), a pentagonal substance which has been found to be associated with all types of amyloid studied to date. The peripheral 
pattern of AP associated with dystrophic valves has been observed in other types of localised amyloidosis. ${ }^{16} \mathrm{P}$-component is also present in vessel walls, a finding consistent with observations that this substance binds to the microfibrillar mantle of elastic fibres in the skin and blood vessels of normal adults. ${ }^{17}$ The absence of reactivity to anti-AP of the amyloid deposition in one of the mitral valves (case 6 ) is not understood, since neither the clinical nor the histological findings in this patient differed significantly from those of other patients with amyloid positive sclerocalcific valves.

Sclerotic heart valve amyloid appeared chemically distinct from amyloid containing fibril proteins AA, $\mathrm{AL}(\lambda \mathrm{I}, \lambda \mathrm{IV}, \lambda \mathrm{VI}), \mathrm{AE}_{\mathrm{t}}$ and $\mathrm{ASc}$. These results confirm and extend the recent study of Iwata et $a l^{5}$ on amyloid deposits in heart valves. Using the peroxidase-antiperoxidase method, these authors concluded that dystrophic valvular amyloid lacked fibril proteins AA and AL. Since it is known that antisera produced to whole immunoglobulin light chain may fail to detect $\lambda$ or $\kappa$ light chain fragments in amyloid, specific antisera produced from three subclasses of amyloid fibril protein $A \lambda$ were used in these studies. The lack of reaction with anti-HPA indicates that the amyloid of sclerotic heart valves differs from the generalised form of senile cardiac amyloid. The latter form of amyloid has been shown to contain the fibril protein $\mathrm{ASc}$, which possesses structural $^{18}$ and immunological ${ }^{19}$ similarity to HPA.

Autofluorescence of amyloid deposits is a well known phenomenon, especially following formalin fixation. However, with the exception of mature plaques of senile dementia, ${ }^{20}$ ethanol-fixed fresh or frozen tissues generally show little or no background fluorescence. Sclerocalcific heart valves, on the other hand, showed a high degree of autofluorescence, presumably related to the presence of scar tissue. This problem was eventually overcome by using fluorescence Congo red prestaining and specific FITC immunofluorescence on the same tissue sections. This method has proved useful for locating small foci of amyloid in a background of dense fibrous tissue prior to assessing immunofluorescence reactivity. ${ }^{21}$

The discovery of a dystrophic form of heart valve amyloidosis raises the possibility that the same type of amyloid deposition could be associated with other degenerative lesions. The uniform presence of amyloid in the aging aorta ${ }^{2122}$ suggests a mechanism of amyloidogenesis similar to that associated with atherosclerosis. ${ }^{22}$ The presence of amyloid in calcified porcine bioprotheses implanted in humans (Goffin $e t$ al, unpublished observation) may represent yet another example of amyloid deposition as an integral process in the development of, or the response to, degenerative change.

We wish to thank Joan Johnson and Kate Connolly for their excellent technical assistance and Ulla Burnham for preparation of the manuscript.

\section{References}

' Buja LM, Khol MB, Roberts W. Clinically significant cardiac amyloidosis. Clinicopathological findings in 15 patients. Am J Cardiol 1970;26:394-405.

${ }^{2}$ Goffin YA. Microscopic amyloid deposits in heart valves: a common local complication of chronic damage and scarring. $J$ Clin Pathol 1980;33:262-8.

${ }^{3}$ Cooper JH. Localised amyloidosis of chronically diseased heart valves. XIII International Congress of the International Academy of Pathology, Paris 1980.

${ }^{4}$ Falk E, Ladefoged C, Christensen HE. Amyloid deposits in calcified aortic valves. Acta Pathol Microbiol Scand [A] 1981;89:23-6.

s Iwata T, Nakamura H, Nagasawa T, et al. Amyloid deposits in heart valves. Acta Pathol Jpn 1982;32:23-9.

- Sante-Marie G. A paraffin embedding technique for studies employing immunofluorescence. $J$ Histochem Cytochem 1962;10:250-6.

7 Wright JR, Calkins E, Humphrey RL. Potassium permanganate reaction in amyloidosis. A histologic method to assist in differentiating forms of this disease. Lab Invest 1977;36:274-81.

8 Adams CWM. A p-dimethylaminobenzaldehyde-nitrate method for the histochemical demonstration of tryptophan and related component. J Clin Pathol 1957;10:56-62.

${ }^{9}$ Cornwell GG III, Husby G, Westermark P, Natvig Jळ్ Michaelsen TE, Skogen B. Identification and characterisatio of different amyloid fibril proteins in tissue sections. Scand $\AA$. Immunol 1977;6:1071-80.

${ }^{10}$ Cornwell GG III, Natvig JB, Westermark P, Husby G. Senile cardiac amyloid: demonstration of a unique fibril protein in tissue sections. J Immunol 1978;120:1385-8.

"Pitkaenen P, Westermark P, Cornwell GG III, Murdoch W. Amyloid of the seminal vesicles: a distinctive and common localised form of senile amyloidosis. J Clin Pathol 1983;110:64-9.

${ }_{12}$ Narang HK. High-resolution electron microscopic analysis of amyloid fibril in Alzheimer's disease. J Neuropathol Exp Neurol 1980;621-31.

${ }^{13}$ Pearse AGE, Ewen SW, Polak JM. The genesis of apudamyloid endocrine polypeptide tumors: histochemical distinction from immunoamyloid. Virchows Arch 1972;B-10:303-7.

14 Westermark P, Johansson B, Natvig JB. Senile cardiac amyloidosis: Evidence of 2 different amyloid substances in the aging heart Scand J Immunol 1975;10:303-8.

${ }^{15}$ Powers JM, Spicer SS. Histochemical similarity of senile plaque amyloid to apudamyloid. Virchows Arch Pathol Anat 1977;376:107-15.

${ }^{16}$ Westermark P, Shirahama T, Skinner M, Noren P, Cohen AS Amyloid $\mathbf{P}$ component (Protein AP) in localised amyloidosis as revealed by an immunocytochemical method. Histochemistry 1981;71:171-5.

${ }^{17}$ Breathnach SM, Melrose SM, Bhogal B, de Beer FC, Dyck RF, N Tennent C, Black MM, Pepys MB. Amyloid P component is located on elastic fibre microfibrils in normal human tissue. Nature 1981;292:652-4.

${ }^{18}$ Sletten K, Westermark P, Natvig JB. Senile cardiac amyloid is related to prealbumin. Scand J Immunol 1980;12:503-6.

${ }^{19}$ Cornwell GG III, Westermark P, Natvig JB, Murdoch W. Senile $\varrho$ cardiac amyloidosis: evidence that fibrils contain a protein immunologically related to prealbumin. Immunology $1981 ; 44: 447-52$. 
${ }^{20}$ Probst A, Heitz PU, Ulrich J. Histochemical analysis of senile plaque amyloid and amyloid angiopathy. Virchows Arch $A$ Pathol Anat Hist 1980;388:327-34.

${ }^{21}$ Cornwell GG III, Westermark P, Murdoch W, Pitkaenen P. Senile aortic amyloid: a third distinctive type of age-related cardiovascular amyloid. Am J Pathol 1982;108:135-8.
${ }^{22}$ Wright JR, Calkins E, Breen WJ, Stolte G, Schultz RT. Relationship of amyloid to aging. Medicine 1969;48:39-60.

Requests for reprints to: Dr YA Goffin, Department of Pathology, Hôpital Brugmann, Université Libre de Bruxelles, 1020 Brussels, Belgium. 